\title{
Improved Reactivity of Cellulose via Its Crystallinity Reduction by Nondissolving Pretreatment with an Ionic Liquid
}

\section{Pena, Carlos A.}

2019-05-20

Pena , C A , Soto , A , King , A W T \& Rodriguez , H 2019 , ' Improved Reactivity of Cellulose via Its Crystallinity Reduction by Nondissolving Pretreatment with an Ionic Liquid ' , ACS Sustainable Chemistry \& Engineering , vol. 7 , no. 10 , pp. 9164-9171 . https://doi.org/10.1021/acssuschemeng

http://hdl.handle.net/10138/307296

https://doi.org/10.1021/acssuschemeng.8b06357

acceptedVersion

Downloaded from Helda, University of Helsinki institutional repository.

This is an electronic reprint of the original article.

This reprint may differ from the original in pagination and typographic detail.

Please cite the original version. 


\section{Improved Reactivity of Cellulose via its Crystallinity Reduction}

\section{by Non-Dissolving Pretreatment with an Ionic Liquid}

Carlos A. Pena, ${ }^{\dagger}$ Ana Soto,${ }^{\dagger}$ Alistair W. T. King, ${ }^{\ddagger}$ and Héctor Rodríguez ${ }^{*} \dagger$

$\dagger$ Department of Chemical Engineering, Universidade de Santiago de Compostela, E-15782,

Santiago de Compostela, Spain

* Department of Chemistry, University of Helsinki, A. I. Virtasen Aukio 1, 00014 Helsinki,

Finland

* Corresponding author. E-mail: hector.rodriguez@usc.es. Phone: +34 881816804. 


\section{ABSTRACT}

The improvement of the reactivity of cellulose by means of an efficient pretreatment method is critical for the optimal valorisation of this biorenewable polymer within a biorefinery context. In this work, a non-dissolving procedure for the pretreatment of cellulose, based on the direct solid-liquid contact of cellulose with an ionic liquid, namely tetrabutylphosphonium acetate, or with its mixtures with water or dimethylsulfoxide, was found to lead to an effective reduction of the cellulose crystallinity. Due to the non-dissolving nature of the method, the cellulose thus pretreated can be simply recovered by filtration from the pretreatment fluid. The use of the molecular cosolvents, as compared to the use of the neat ionic liquid, results in a less viscous pretreatment fluid and also in a larger reduction of the cellulose crystallinity. An improvement in the reactivity of the pretreated cellulose was evidenced via the determination of the kinetics of an enzymatic hydrolysis. A relationship between this reaction kinetics and the degree of crystallinity of the cellulose was inferred: the lower the crystallinity, the faster the hydrolysis. The thermal stability and degree of polymerisation of the pretreated cellulose samples were comparable or essentially unaltered with respect to the untreated cellulose.

KEYWORDS: Cellulose, tetrabutylphosphonium, crystallinity index, enzymatic hydrolysis, degree of polymerisation

\section{INTRODUCTION}

Cellulose is an abundant, geographically-distributed and biorenewable resource with the potential to be used as raw material for the sustainable production of numerous chemical 
products, within a biorefinery context. ${ }^{1}$ However, this potential is limited by the fact that cellulose is present in nature with a high proportion of the 'cellulose I' crystalline allomorphs. ${ }^{2,3}$ This is preserved in the current methods of isolating cellulose from the native lignocellulosic matrices and imposes a substantial limitation to its chemical reactivity, and general transformation into value-added chemicals. ${ }^{4}$ In order to increase this reactivity, cellulose is typically pretreated to transform the cellulose I form mainly into the more thermodynamically stable and more accessible crystalline form denominated 'cellulose II'; although a reduction in cellulose crystallinity to yield amorphous cellulose would be much more desirable, as kinetics of reaction should increase well beyond that for cellulose II. The current pretreatment methods can be based in two different approaches: dissolution followed by rapid regeneration, through a precipitation mechanism; or mercerisation (a non-dissolving procedure typically using aqueous $\mathrm{NaOH}$ solutions). ${ }^{6,7}$ In either case these procedures typically involve the utilisation of strong bases or acids, and harsh operation conditions.

The discovery of novel fluid media capable of dissolving cellulose without derivatisation (e.g. ionic liquids, aqueous onium hydroxydes, concentrated acids...) has raised interest in the development of new dissolution-based processes in recent years. ${ }^{4}$ However, the need to precipitate the dissolved cellulose from solution requires the utilisation of an antisolvent (water being probably the most popular), which will inevitably mean an important energy penalty associated with the solvent recovery stage. In addition, the simple addition of water as antisolvent often results in gelation, which complicates the biomass recovery due to limited mass transfer. Although this can be alleviated using different antisolvent compositions, ${ }^{8}$ it will inherently introduce undesirable further complications in the recycling 
process. Within that context, a mercerisation-type (i.e. non-dissolving) process would be more advantageous, as the cellulose could be mainly recovered by pressing and/or filtration.

After the first report of cellulose dissolution in ionic liquids, without derivatisation and under mild conditions, ${ }^{9}$ with its regeneration in the form of cellulose II, these low-melting salts have attracted attention as potential fluids in technologies for cellulose pretreatment. So far, the focus in this regard has been limited to ionic liquids with the ability to dissolve cellulose,$^{10}$ thus sharing the problems mentioned above for pretreatment schemes based on dissolution and subsequent regeneration, which neutralises the advantage of using a nonvolatile, non-flammable ionic liquid as a safer pretreatment fluid. However, the capacity of ionic liquids to interact with cellulose does not have to be limited to those able to dissolve it in appreciable concentrations. This would be similar to a strategy already insinuated in research works for the pretreatment of lignocellulosic materials, where other ionic liquids were considered in addition to those able to dissolve cellulose in relevant concentrations. Such is the case, for instance, of choline acetate and choline lysinate, with negligible capacity for cellulose dissolution, ${ }^{11,12}$ but efficient in pretreating/delignifying switchgrass, and for which an effective interaction with the crystalline structure of cellulose in that context was evidenced through X-ray diffraction analyses. ${ }^{13}$ Nevertheless, a specific study on the phenomenon of cellulose crystallinity disruption has not been carried out to date. For the case of pretreatment of isolated cellulose in the context of cellulose processing industry, some tetraalkylphosphonium acetates could be ionic liquid candidates of great potential, as they have been found not to dissolve cellulose when in neat, but to be capable of dissolving it when combined with specific cosolvents. ${ }^{14,15}$ 
On the assumption of such interaction ability, one of those ionic liquids is explored in this work as a pretreatment fluid for cellulose in a mercerisation-type process. In particular, tetrabutylphosphonium acetate $\left(\left[\mathrm{P}_{4444}\right][\mathrm{OAc}]\right)$ has been selected, as it has been reported to exhibit low toxicity towards a number of microorganisms (in contrast to some of its homologues incorporating longer alkyl substituents). ${ }^{16,17}$ The effectiveness of a pretreatment based on the simple contact of cellulose and the ionic liquid, with easy recovery of the pretreated cellulose by filtration, will be evaluated through the analysis of the cellulose crystallinity reduction. The improvement in the reactivity of the pretreated cellulose will be evaluated through an enzymatic hydrolysis reaction. The use of molecular cosolvents, such as water (polar protic solvent) and DMSO (dipolar aprotic solvent), at $20 \mathrm{~mol} \%$ and $40 \mathrm{~mol} \%$ concentrations, will be also investigated. Attention will be paid to the preservation of the degree of polymerisation of cellulose, as well as to the confirmation of the non-dissolving character of the pretreatment.

\section{EXPERIMENTAL SECTION}

Materials. The ionic liquid $\left[\mathrm{P}_{4444}\right][\mathrm{OAc}]$ was synthesised by a metathesis reaction between tetrabutylphosphonium chloride (Iolitec, $>95 \%$ ) and potassium acetate (SigmaAldrich, $99 \%$ ), following a similar procedure to that described elsewhere. ${ }^{16}$ Experimental details on the synthesis are provided in the Supporting Information, including ${ }^{1} \mathrm{H}$ and ${ }^{13} \mathrm{C}$ NMR spectra of the final product (Figures S1 and S2). DMSO was purchased from SigmaAldrich with nominal purity $99.99 \%$, and used as received. Double-distilled water was used throughout this work. Microcrystalline cellulose (MCC) was supplied by Sigma-Aldrich and, prior to use, it was subjected to a drying process in an oven at $110^{\circ} \mathrm{C}$ to a residual water 
content of ca. $1.5 \%$, as determined by the weight loss observed in a thermogravimetric analysis (TGA) experiment (heating at $20{ }^{\circ} \mathrm{C} / \mathrm{min}$ from room temperature to $110{ }^{\circ} \mathrm{C}$, followed by a 60 -min isotherm). See below the TGA experimental details.

Thermal and physical properties. The thermal stability of the ionic liquid and of the cellulose samples was determined by TGA in a TA Instruments Q500 thermogravimetric analyser. For the determination of melting temperatures, differential scanning calorimetry (DSC) analyses were carried out in a TA Instruments Q2000 differential scanning calorimeter with an RCS 90 refrigerated cooling system attached. Kinematic viscosities $(v)$ were measured with micro-Ubbelohde glass capillary viscometers at controlled temperatures, using an automatic Lauda PVS1 Process Viscosity System equipped with a photoelectric cell for the precise determination of the efflux time of the liquid samples through the viscometers. Dynamic viscosities $(\eta)$ were then obtained as the product of $v$ by the density $(\rho)$; the latter being measured in an Anton Paar vibrating U-tube DMA 5000 density meter with automatic correction of the influence of the viscosity and a built-in system based on the Peltier effect to keep a controlled temperature.

Further details on the experimental setups and procedures can be found in the Supporting Information.

Pretreatment of cellulose. Neat $\left[\mathrm{P}_{4} 4_{4}\right][\mathrm{OAc}]$ and its mixtures with water or with DMSO (at mole fractions of 0.20 and 0.40 of the molecular cosolvent) were tested as pretreatment solvents for MCC. In each pretreatment experiment, $10.0 \mathrm{~g}$ of one of these solvents was placed in a jacketed glass cell. $1.00 \mathrm{~g}$ of MCC was added, thus making a solidto-liquid ratio of $10 \mathrm{~g}$ of solid per $100 \mathrm{~g}$ of solvent. The cell was stoppered and its contents were thermostated at $70{ }^{\circ} \mathrm{C}$ by means of water from a Selecta Ultraterm 200 thermostatic bath 
circulating through its jacket. Mechanical stirring (ca. $300 \mathrm{rpm}$ ) was used to maximise good solid-liquid contact in the heterogeneous mixture. After the desired pretreatment time $(2 \mathrm{~h}$, $4 \mathrm{~h}$, or $8 \mathrm{~h}$ ), the solid was recovered by simple filtration under soft vacuum, through a fritted glass Allihn filter tube. To avoid interferences of residual solvent in further characterisation, the recovered solid was washed with portions of $50 \mathrm{~mL}$ of water, until the absorbance of the washings at $200 \mathrm{~nm}$ (carried out in an Agilent $8453 \mathrm{UV}$-vis spectrophotometer equipped with a deuterium plasma discharge lamp, for such wavelengths) corresponded to a concentration lower than $50 \mathrm{ppm}$ of ionic liquid, in accordance with a calibration curve previously carried out (see Table S1 and Figure S3 in the Supporting Information). In those cases in which the mixture of ionic liquid and DMSO was used as pretreatment fluid, the pretreated cellulose was also subjected to sulfur analysis in a Thermo Finnigan Flash 1112 elemental analyser, to verify the absence of DMSO (detection threshold: $100 \mathrm{ppm}$ ). The washed cellulose sample was finally dried in an oven at $110^{\circ} \mathrm{C}$, with manual soft grinding intercalated to avoid agglomeration of particles, until a water content similar to the non-pretreated cellulose was observed (vide supra).

In parallel, with an analogous setup, the (in)ability of [ $\left.\mathrm{P}_{4444}\right][\mathrm{OAc}]$ and its investigated mixtures with water or DMSO to dissolve cellulose was explored. For such a purpose, ca. $0.02 \mathrm{~g}$ of cellulose was added into the glass cells, thermostated at $70^{\circ} \mathrm{C}$, containing a certain amount of the particular solvent, rendering a final ratio of $0.5 \mathrm{~g}$ of cellulose per $100 \mathrm{~g}$ of solvent in the system. The heterogeneous mixture was magnetically stirred at ca. $300 \mathrm{rpm}$ for $24 \mathrm{~h}$, and then a sample was taken and analysed by confocal microscopy in a Leica TCS SP5 X microscope using a UV $405 \mathrm{~nm}$ diode and a Scan-DIC-Pol filter. 
All weighing was carried out in a Mettler-Toledo XPE 205 analytical balance precise to within $1 \times 10^{-4} \mathrm{~g}$.

\section{Characterisation of the cellulose samples: crystallinity index and degree of} polymerisation. The crystallinity index $(C I)$ of the cellulose samples, i.e. the percentage of crystalline material present in those samples, was determined by means of the method based on powder X-ray diffractometry (PXRD) with subtraction of the amorphous component, which is currently considered to lead to the numerically more reliable results. ${ }^{7,18}$ The degree of polymerisation $(D P)$, interpreted as the average of the number of glucose units of the cellulose chains in a given sample, was determined through a procedure ${ }^{19}$ based on the solubilisation, in an inert atmosphere of argon (Praxair, 3X quality), of a small amount of cellulose in a $0.5 \mathrm{M}$ aqueous solution of bis(ethylenediamine)copper(II) hydroxide (supplied by Sigma-Aldrich with a concentration of $1.0 \mathrm{M}$ ). Further experimental details can be found in the Supporting Information.

Kinetics of hydrolysis of cellulose samples. Cellulose $(0.20 \mathrm{~g})$ was added to $6.67 \mathrm{~g}$ of aqueous citrate buffer 0.01 M (made with citric acid (Sigma-Aldrich, $99.5 \%$ ) and sodium citrate (Sigma-Aldrich, $99 \%)$ ) at pH 5 in a jacketed glass cell. The content of the cell was thermostated at $50^{\circ} \mathrm{C}$, and magnetically stirred (ca. $300 \mathrm{rpm}$ ). A combination of cellulase (Celluclast 1.5L, by Novozymes) and $\beta$-glucosidase (NS50010, by Novozymes) was used to perform the enzymatic hydrolysis. The concentration of glucose in the medium was monitored by taking samples at different times and analysing their glucose content with a commercial enzymatic kit by Spinreact. See further experimental details in the Supporting Information. 


\section{RESULTS AND DISCUSSION}

Thermal characterisation of the ionic liquid [ $\left.\mathbf{P}_{44} 4_{4}\right][$ [OAc]. As commented in the Experimental Section, the purified $\left[\mathrm{P}_{4} 4_{4}\right][\mathrm{OAc}]$ is solid at room temperature. To determine the temperature range in which it can be utilised as a stable liquid, its solid/liquid transition and its thermal stability were analysed by DSC and TGA respectively. (The corresponding thermograms are available as Figures S4 and S5 in the Supporting Information.) From the DSC analysis, an onset melting temperature of $56^{\circ} \mathrm{C}$ was found. Regarding the thermal stability, an onset decomposition temperature of $317^{\circ} \mathrm{C}$ was found. If an onset with the tangent to the TGA curve at the point of $5 \%$ decomposition is used, instead of the regular onset with the tangent at the inflection point, the so-called $5 \%$ onset decomposition temperature $\left(T_{d, 5 \% \text { onset }}\right)$ can be obtained, which is a more conservative and realistic value of the maximum temperature at which the ionic liquid can be actually used in mid- or long-term

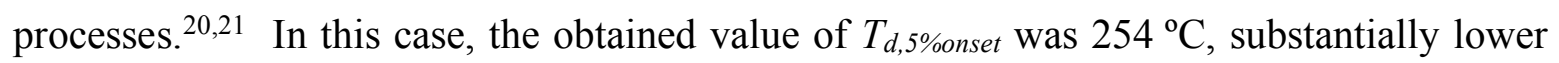
than the regular onset decomposition temperature. However, even the $T_{d, 5 \%}$ onset value corresponds to a dynamic TGA experiment. To further guarantee the thermal stability of the ionic liquid in cellulose pretreatments which are going to last for several hours, isothermal TGA runs with a duration of $24 \mathrm{~h}$ were performed at different temperatures lower than the

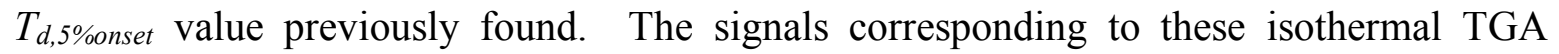
experiments are shown in Figure 1, where it can be observed that the ionic liquid undergoes substantial decomposition at temperatures notably lower than $T_{d, 5 \% \text { onset }}$ (for example, decomposition of a large percent of the initial sample is observed at $190{ }^{\circ} \mathrm{C}$ or $210{ }^{\circ} \mathrm{C}$ after the first hours). A negligible decomposition rate was observed at $130^{\circ} \mathrm{C}$ (higher than e.g. the temperature of $110^{\circ} \mathrm{C}$ found under an analogous analysis for the archetypal ionic liquid 
1-ethyl-3-methylimidazolium acetate) ${ }^{21}$. Therefore, this value can be taken as a better estimation of the maximum temperature at which a process involving $\left[\mathrm{P}_{4444}\right][\mathrm{OAc}]$ should be operated.

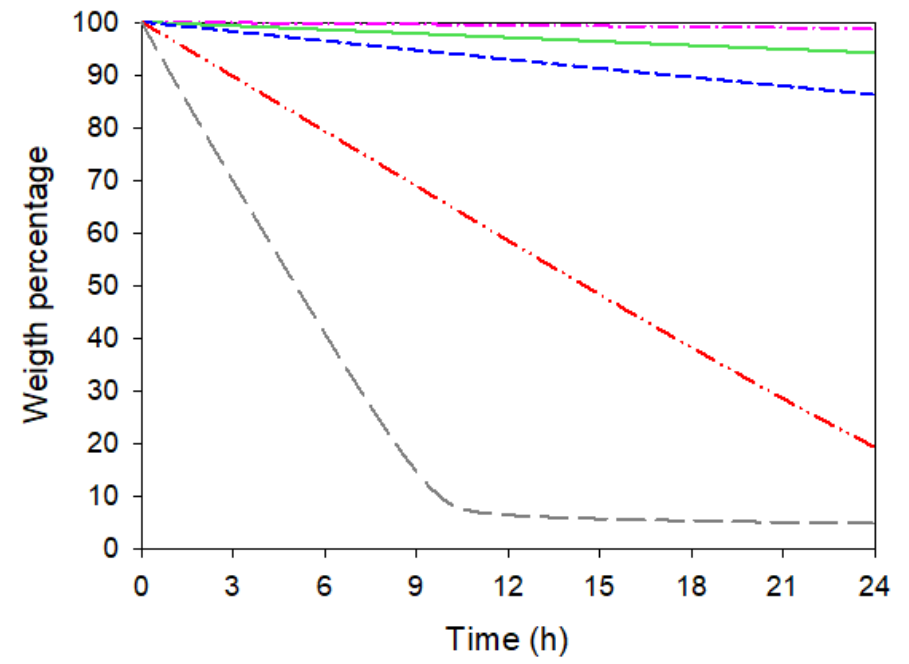

Figure 1. Isothermal TGA curves for $\left[\mathrm{P}_{44} 4\right][\mathrm{OAc}]$, at different temperatures (from top to bottom): $130{ }^{\circ} \mathrm{C}$ (magenta, dot-dash line), $150{ }^{\circ} \mathrm{C}$ (green, solid line), $170{ }^{\circ} \mathrm{C}$ (blue, short-dashed line), $190{ }^{\circ} \mathrm{C}$ (red, dot-dot-dash line), and $210{ }^{\circ} \mathrm{C}$ (gray, long-dashed line).

In view of the above, a compromise temperature of $70{ }^{\circ} \mathrm{C}$ was selected to carry out the cellulose pretreatment experiments. This was a temperature intended to keep to a minimum the cost of heating of the system, while being sufficiently above the reported melting temperature and safely below the temperature of $130{ }^{\circ} \mathrm{C}$ for which practically negligible thermal decomposition was observed over the 24-hour isothermal TGA analysis. (Interestingly, by modelling the kinetics of thermal decomposition of the ionic liquid with the Arrhenius equation by means of the procedure reported by Clough et al., ${ }^{21}$ an extrapolated 
time of $5000 \mathrm{~h}$ would be necessary for the ionic liquid to undergo a $1 \%$ decomposition at the selected temperature of $70{ }^{\circ} \mathrm{C}$. The details of this calculation, including Figures S6 and S7, are provided in the Supporting Information.) Moreover, it is worth noting that this is a temperature lower than the ones typically used in pretreatment of cellulose with ionic liquids. ${ }^{11}$

Pretreatment with neat [ $\left.\mathbf{P}_{4} 4_{4} 4\right][O A c]$ : effect of time. Different pretreatment times $(2 \mathrm{~h}, 4 \mathrm{~h}$, and $8 \mathrm{~h})$ were investigated in the pretreatment of the cellulose with neat $\left[\mathrm{P}_{4} 4_{4}\right][$ OAc]. The PXRD diffractograms obtained for the pretreated samples are shown in Figure 2, along with the diffractogram corresponding to the untreated cellulose. A gradual decrease in the intensity of the crystalline peaks with an increase in the pretreatment time is clearly observed. The $C I$ values associated were calculated to be: $48 \%$ for the untreated sample; $38 \%$ for the 2 -hour pretreatment, $30 \%$ for $4 \mathrm{~h}$, and $24 \%$ for $8 \mathrm{~h}$. Thus, the simple, non-dissolving pretreatment with pure $\left[\mathrm{P}_{4} 4_{4}\right][\mathrm{OAc}]$ leads to a significant decrease in the degree of crystallinity of cellulose upon pretreatment, at any of the tested pretreatment times.

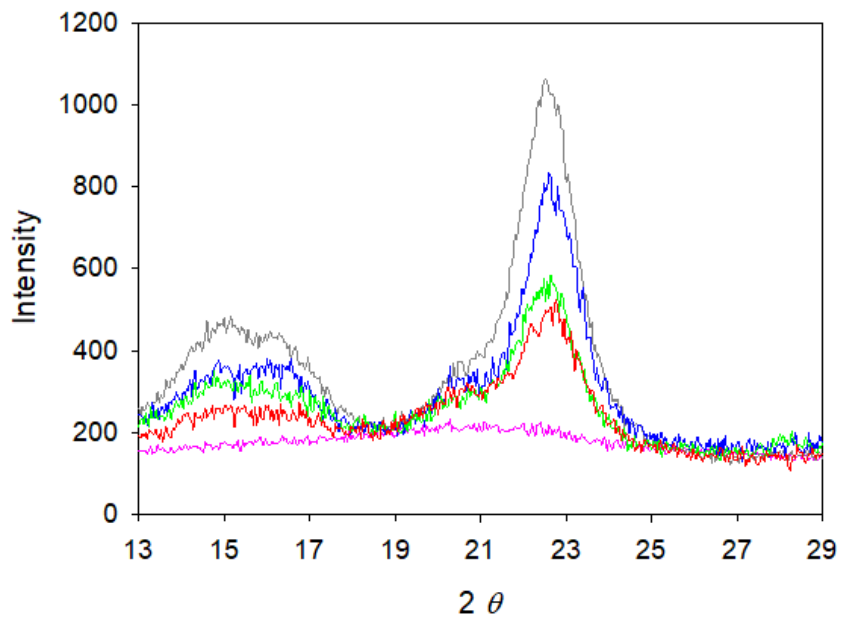


Figure 2. PXRD diffractograms of cellulose pretreated with pure $\left[\mathrm{P}_{4444}\right][\mathrm{OAc}]$ at $70{ }^{\circ} \mathrm{C}$, with a load of $10 \mathrm{~g}$ of cellulose per $100 \mathrm{~g}$ of ionic liquid, during different times. From top to bottom at a $2 \theta$ value of $23^{\circ}$ : without pretreatment (gray), $2 \mathrm{~h}$ (blue), $4 \mathrm{~h}$ (green), $8 \mathrm{~h}$ (red). The diffractogram of amorphous cellulose is also shown (magenta).

To find out if the observed reduction in the degree of crystallinity translated into an improved reactivity of the cellulose, the enzymatic hydrolysis of cellulose by the action of cellulases and $\beta$-glucosidases was selected as a model reaction. (It must be noted that this enzymatic hydrolysis was chosen only for the sake of evidencing an improved reactivity; not as a process target in itself, as it is normally the case in works involving the pretreatment and subsequent saccharification of lignocellulosic biomass.) Thus, a study of the kinetics of enzymatic hydrolysis of the pretreated cellulose samples was carried out. The corresponding time courses are shown in Figure 3, together with the base case of hydrolysis of untreated cellulose. As observed, all pretreated cellulose samples hydrolysed at a faster rate than the untreated cellulose. For a given time, the higher the length of the pretreatment time, the higher the conversion achieved. This evolution of hydrolysis kinetics is in line with the degrees of decrystallisation described in the paragraph above. 


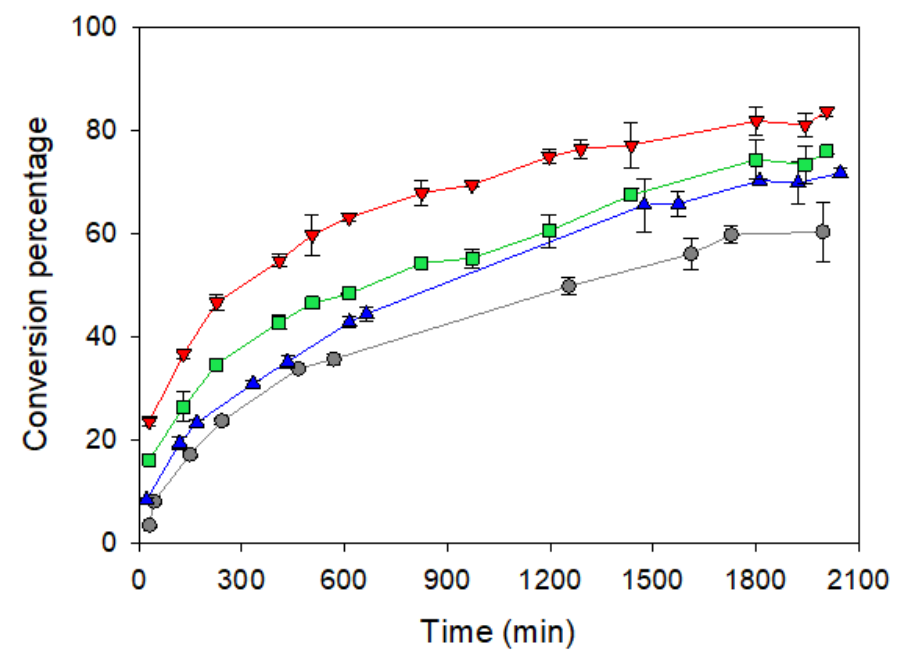

Figure 3. Evolution, as a function of time, of the percentage of conversion of cellulose into glucose in the reaction of enzymatic hydrolysis of the cellulose pretreated with pure $\left[\mathrm{P}_{4444}\right][\mathrm{OAc}]$ at $70{ }^{\circ} \mathrm{C}$ during different pretreatment times: $2 \mathrm{~h}$ (blue, triangles), $4 \mathrm{~h}$ (green, squares), and $8 \mathrm{~h}$ (red, inverted triangles). The kinetics of hydrolysis of untreated cellulose are also shown (gray, circles).

Given the interest, for many applications, of pretreatment procedures that do not affect negatively the length of the cellulose chains, an investigation of the $D P$ was also carried out. Values of 224, 228, and 224 were respectively found for the cellulose samples pretreated during 2,4 , and $8 \mathrm{~h}$. If the uncertainty of the method for the experimental determination of $D P$ is taken into account, all these values can be considered as equivalent and not significantly different than the value of 228 found for the untreated cellulose. Therefore, it can be assumed that the cellulose chains were not degraded during the pretreatments at $70^{\circ} \mathrm{C}$.

Similarly, another aspect of interest may be that the pretreatment does not affect the thermal stability of the cellulose. The determination of the $T_{d, 5 \% \text { onset }}$ for the cellulose samples pretreated during different times was carried out, and the following values were obtained: 
$289^{\circ} \mathrm{C}$ for the cellulose samples pretreated during $2 \mathrm{~h}$ and during $4 \mathrm{~h}$, and $286{ }^{\circ} \mathrm{C}$ for the sample corresponding to the pretreatment during $8 \mathrm{~h}$. This means just a very small decrease (essentially negligible for practical purposes) in thermal stability with regard to the $T_{d, 5 \% o n s e t}$ of $296^{\circ} \mathrm{C}$ obtained for the untreated cellulose; and it constitutes and advantage of the method reported herein with respect to other strategies previously reported for cellulose decrystallisation with ionic liquids. ${ }^{11}$

In a further consideration, and to verify the non-dissolving nature of the pretreatment method proposed, a test for evaluation of the capacity of [ $\left.\mathrm{P}_{44} 4_{4}\right][\mathrm{OAc}]$ for dissolution of cellulose was performed. Figure S8 in the Supporting Information is a microscopic photograph of a mixture of $0.5 \mathrm{~g}$ of cellulose and $100 \mathrm{~g}$ of $\left[\mathrm{P}_{44_{4}}\right]$ [OAc] after vigorous stirring for $24 \mathrm{~h}$ at $70{ }^{\circ} \mathrm{C}$. The clear observance of undissolved microcrystalline solids is evidence of the negligible cellulose dissolution capacity of [ $\left.\mathrm{P}_{4} 4_{4}\right][\mathrm{OAc}]$ (lower than $0.5 \mathrm{~g}$ of cellulose per $100 \mathrm{~g}$ of ionic liquid), and thus the non-dissolving character of the proposed pretreatment can be assumed.

\section{Effect of water or DMSO as cosolvents of [ $\left.P_{4} 4_{4} 4_{4}\right][O A c]$ in the pretreatment fluid.}

Besides the use of neat $\left[\mathrm{P}_{4444}\right][\mathrm{OAc}]$ as fluid for the non-dissolving pretreatment of cellulose, some mixtures of this ionic liquid with water or DMSO were also tested for such purpose. The use of these molecular cosolvents would lead to a series of beneficial aspects: lowering the cost per unit mass, lowering the melting temperature of the fluid (as dictated by the colligative properties), and lowering of the viscosity. The latter was experimentally quantified for mixtures with mole fractions of cosolvent of 0.20 and 0.40 , with Table 1 providing a comparison of the dynamic viscosities of the neat ionic liquid and of the selected mixtures at the common temperature of $70{ }^{\circ} \mathrm{C}$ (where all systems are totally fluid). A 
remarkable decrease in viscosity is observed, regardless of whether water or DMSO are used as cosolvents, even for the lowest cosolvent mole fraction tested. The density of the studied mixtures, also experimentally determined since it was necessary for the calculation of the dynamic viscosity, is also included in Table 1; although in the case of this property the influence of the cosolvents is more limited.

Table 1. Density $(\rho)$ and dynamic viscosity $(\eta)$ at $70^{\circ} \mathrm{C}$ for pure $\left[\mathrm{P}_{44_{4}}\right][\mathrm{OAc}]$ and for its mixtures with water or DMSO at selected mole fractions $\left(x_{2}\right)$ of the molecular cosolvent; and crystallinity index $(C I)$ and degree of polymerisation $(D P)$ of the cellulose pretreated with those fluids at $70^{\circ} \mathrm{C}$ for $2 \mathrm{~h}$ with a load of $10 \mathrm{~g}$ of cellulose per $100 \mathrm{~g}$ of solvent.

\begin{tabular}{lccccc}
\hline Cosolvent & $x_{2}$ & $\rho\left(\mathrm{g} / \mathrm{cm}^{3}\right)$ & $\eta(\mathrm{mPa} \cdot \mathrm{s})$ & $C I(\%)$ & $D P$ \\
\hline None & --- & 0.90886 & 43.90 & 38 & 224 \\
Water & 0.20 & 0.91084 & 31.12 & 31 & 228 \\
Water & 0.40 & 0.91316 & 22.78 & 34 & 226 \\
DMSO & 0.20 & 0.91603 & 28.85 & 12 & 219 \\
DMSO & 0.40 & 0.92530 & 18.81 & --- & --- \\
\hline
\end{tabular}

For the evaluation of the effect of the molecular cosolvents in the pretreatment of cellulose, the temperature of $70^{\circ} \mathrm{C}$ was chosen to allow direct comparison with the pretreatment carried out with the neat ionic liquid (despite the fact that lower temperatures could be an option if using the mixtures of ionic liquid and molecular cosolvent). Although the pretreatment efficiency (crystallinity reduction) with neat [ $\left.\mathrm{P}_{4444}\right]$ [OAc] was more effective at longer times, for this new set of pretreatments a duration of $2 \mathrm{~h}$ was preferred considering the overall energy demands and productivity in an industrial context. 
Figure 4 shows the PXRD diffractograms of the cellulose samples pretreated with the mixtures of $\left[\mathrm{P}_{44_{4}}\right][\mathrm{OAc}]+\mathrm{H}_{2} \mathrm{O}$. Compared to the cellulose pretreated with pure ionic liquid, a lower degree of crystallinity is observed. However, the difference between the diffractograms for the two investigated concentrations of water in the mixture is rather small. This has its reflection in the $C I$ values that were calculated, and which are numerically displayed in Table 1. As observed, the $C I$ obtained for cellulose pretreated with the mixtures of ionic liquid and water is clearly lower than that for cellulose pretreated with the neat ionic liquid, but the variation of the concentration of the mixture from a water mole fraction $\left(x_{\text {water }}\right)$ of 0.20 to 0.40 has little influence in the crystallinity reduction achieved. Interestingly, the $C I$ for the pretreatment with the mixture of composition $x_{\text {water }}=0.20$ is slightly lower than that corresponding to the pretreatment with the mixture of composition $x_{\text {water }}=0.40$; a fact that invites us to think of the existence of an optimum composition in the pretreatment system $\left[\mathrm{P}_{4} 4_{4}\right][\mathrm{OAc}]+\mathrm{H}_{2} \mathrm{O}$ for which the reduction in crystallinity is maximised. Such an optimum might be the result of the best balance between the favourable viscosity reduction induced by the presence of water (which improves the contact and absorption of the cellulose with the pretreatment fluid) and the detrimental effect that it would have on the capacity of the pretreatment fluid to interact with the cellulose chains (pure water is totally ineffective as pretreatment fluid!). 


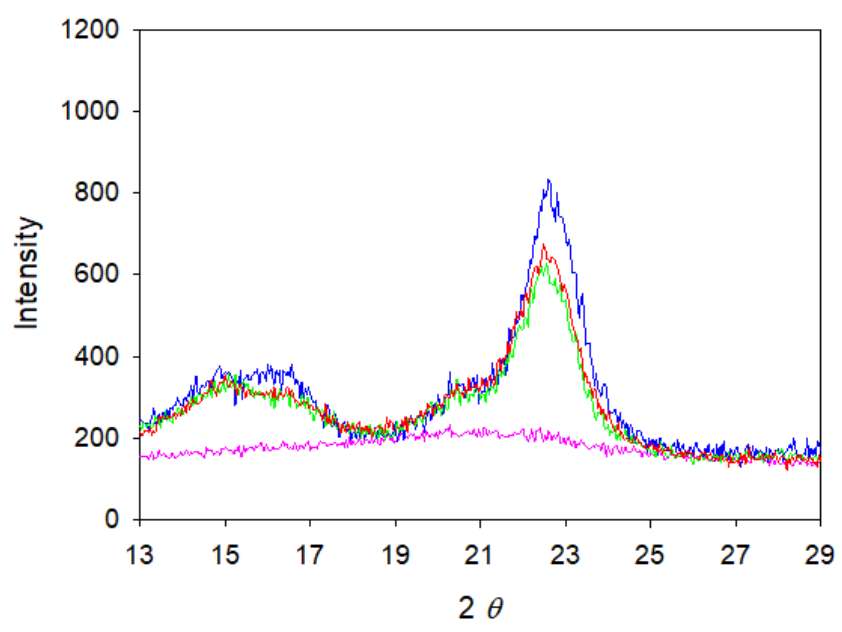

Figure 4. PXRD diffractograms of cellulose pretreated with pure $\left[\mathrm{P}_{4444}\right][\mathrm{OAc}]$ and with mixtures of $\left[\mathrm{P}_{4444}\right][\mathrm{OAc}]+\mathrm{H}_{2} \mathrm{O}$ at different water mole fractions $\left(x_{\text {water }}\right)$, at a temperature $70{ }^{\circ} \mathrm{C}$, with a load of $10 \mathrm{~g}$ of cellulose per $100 \mathrm{~g}$ of solvent, during $2 \mathrm{~h}$. Solvent (from top to bottom at a $2 \theta$ value of $23^{\circ}$ : pure $\left[\mathrm{P}_{4444}\right][\mathrm{OAc}]$ (blue); $\left[\mathrm{P}_{4444}\right][\mathrm{OAc}]+\mathrm{H}_{2} \mathrm{O}, x_{\text {water }}=0.20$ (green); $\left[\mathrm{P}_{4444}\right][\mathrm{OAc}]+\mathrm{H}_{2} \mathrm{O}, x_{\text {water }}$ $=0.40$ (red). The diffractogram of amorphous cellulose is also shown (magenta).

Regarding the system $\left[\mathrm{P}_{44} 4_{4}\right][\mathrm{OAc}]+$ DMSO as pretreatment fluid, an important effect of gelation of cellulose was observed during the washing step when the concentration of 0.40 in mole fraction of DMSO $\left(x_{D M S O}\right)$ was used, thus generating agglomerates that would need copious amounts of water to effectively wash away the retained ionic liquid. This is an indication of partial dissolution and is consistent with our previous reports that demonstrate the requirement for a significant proportion of dipolar aprotic cosolvent, such as DMSO, to maximise cellulose dissolution using all tetraalkylphosphonium acetate homologues. ${ }^{14,15}$ Therefore, further characterisation associated with the pretreatment with such a DMSO concentration was disregarded. With $x_{D M S O}=0.20$ in the pretreatment fluid, an incipient manifestation of gelation could be also observed, but this did not pose a problem in 
performing effectively the washing step. The PXRD diffractogram of the cellulose pretreated with this mixture is shown in Figure 5, where a strong reduction of the area under the curve (directly related to the degree of crystallinity) is observed in comparison to the diffractogram of the cellulose pretreated with pure $\left[\mathrm{P}_{4444}\right][\mathrm{OAc}]$. Moreover, a transition from cellulose I to cellulose II is manifested by the shift of the main peak from $22.5^{\circ}$ (characteristic of cellulose I) to the region $20-21.5^{\circ}$ (characteristic of cellulose II). ${ }^{22}$ As compared to the $C I$ of $38 \%$ obtained when using the neat ionic liquid for the pretreatment, the $C I$ found for the cellulose pretreated with the $\left[\mathrm{P}_{444}\right][\mathrm{OAc}]+\mathrm{DMSO}$ system was very much lower: $12 \%$. Despite this stark crystallinity reduction and the allomorphic transformation from cellulose I to cellulose II, the pretreatment with the explored mixture of $\left[\mathrm{P}_{4444}\right][\mathrm{OAc}]$ and DMSO is still of a non-dissolving nature, based on the avoidance of significant gelation upon regeneration. This aspect was further evidenced through the development of dissolution tests and subsequent analysis by confocal microscopy (Figure S9 in the Supporting Information), where the solubility of cellulose in the $\left[\mathrm{P}_{4444}\right][\mathrm{OAc}]+$ DMSO mixture $\left(x_{D M S O}=0.20\right)$ at $70{ }^{\circ} \mathrm{C}$ was proven to be lower than $0.5 \mathrm{~g}$ of cellulose per $100 \mathrm{~g}$ of solvent. However, the authors air caution that this may be highly temperature dependent. 


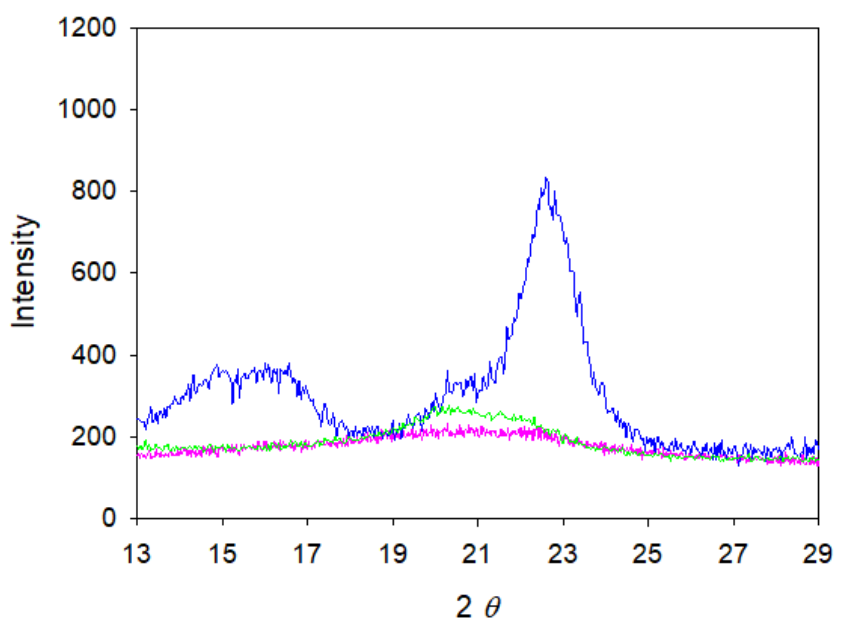

Figure 5. PXRD diffractograms of cellulose pretreated with pure $\left[\mathrm{P}_{4444}\right][\mathrm{OAc}]$ (blue, top signal) and with a mixture of $\left[\mathrm{P}_{44} 4_{4}\right][\mathrm{OAc}]+\mathrm{DMSO}$ at a 0.20 mole fraction of DMSO (green, intermediate signal), at a temperature $70^{\circ} \mathrm{C}$, with a load of $10 \mathrm{~g}$ of cellulose per $100 \mathrm{~g}$ of solvent, during $2 \mathrm{~h}$. The diffractogram of amorphous cellulose is also shown (magenta, bottom signal).

Figure 6 show the kinetics of the enzymatic hydrolysis of the cellulose samples pretreated with mixtures of $\left[\mathrm{P}_{4444}\right][\mathrm{OAc}]$ and water or DMSO, as well as a comparison with the kinetics corresponding to the cellulose pretreated under analogous conditions with neat $\left[\mathrm{P}_{4444}\right][\mathrm{OAc}]$. For both cosolvents, a good correspondence is observed between the level of crystallinity reduction caused by the pretreatment and the improvement in the hydrolysis kinetics. Thus, in the case of water as cosolvent (Figure 6a), the fastest kinetics are found for the cellulose pretreated with the $\left[\mathrm{P}_{4444}\right][\mathrm{OAc}]+\mathrm{H}_{2} \mathrm{O}$ mixture with $x_{\text {water }}=0.20$ (the one for which a lower $C I$ was achieved). The cellulose pretreated with the $\left[\mathrm{P}_{44} 4_{4}\right][\mathrm{OAc}]+\mathrm{H}_{2} \mathrm{O}$ mixture with $x_{\text {water }}=0.40$ leads to somewhat slower kinetics, but still faster than the case of the cellulose pretreated with ionic liquid in the absence of water. Equivalently, in Figure 6b it can be seen how the kinetics of hydrolysis of the cellulose pretreated with the $\left[\mathrm{P}_{44} 4_{4}\right][\mathrm{OAc}]$ 
+ DMSO mixture with $x_{D M S O}=0.20$ (which underwent a very strong reduction in its crystallinity) is much faster than that of the cellulose pretreated with the neat ionic liquid. The strong improvement in the kinetics in this case is likely related not just to the reduction in crystallinity caused by the pretreatment, but may be also related to the transformation of the crystalline fraction from cellulose I to cellulose II (see Figure 5) that concomitantly occurred. ${ }^{4}$ This statement is somewhat controversial, due to the difficulty in separating the effect of the presence of different phases of unambiguously defined crystallinity versus accessibility to enzymes or other reagents. However, it has been reported that higher degrees of oxidation to C6-carboxylates are achievable after TEMPO (2,2,6,6-tetramethyl-1piperidinyloxy) oxidation of mercerised celluloses, compared to untreated technical pulps. ${ }^{23}$ In that report, decreases in the $C I$ of cellulose II during oxidation indicated preferential oxidation of the $\mathrm{C} 6$ position in cellulose II.
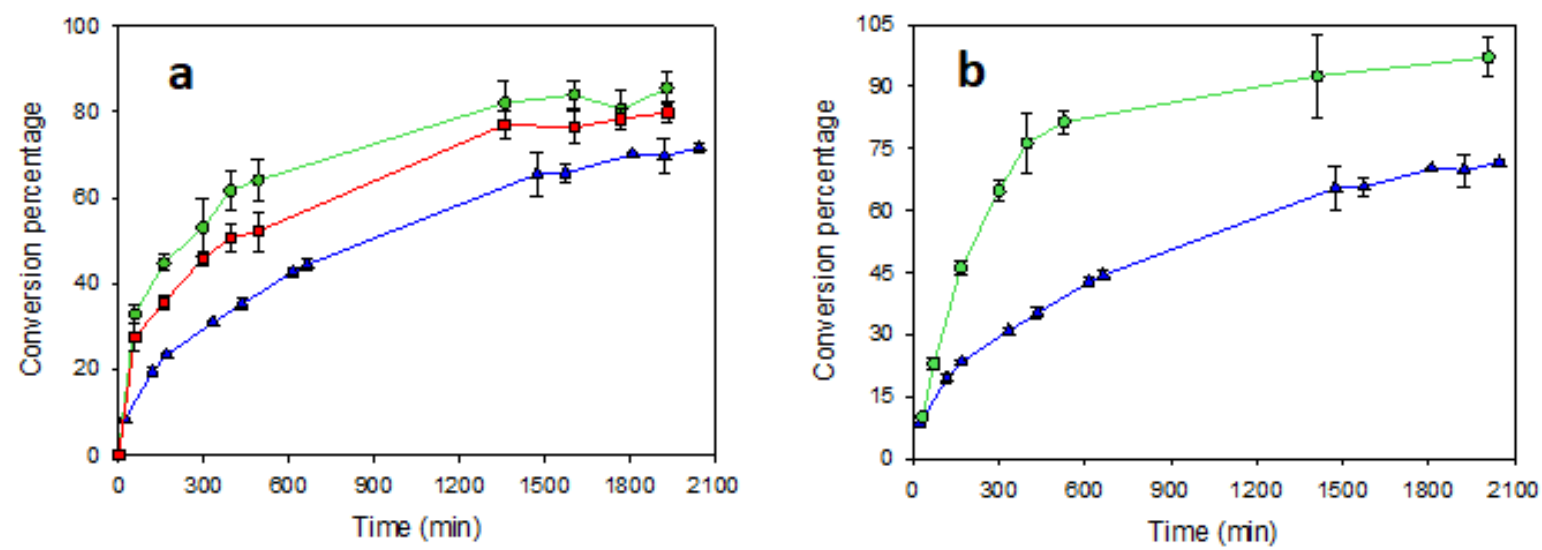

Figure 6. Evolution, as a function of time, of the percentage of conversion of cellulose into glucose in the reaction of enzymatic hydrolysis of the cellulose pretreated, at $70{ }^{\circ} \mathrm{C}$ during $2 \mathrm{~h}$, with pure $\left[\mathrm{P}_{444}\right][\mathrm{OAc}]$ (blue, triangles) and with $\left[\mathrm{P}_{444}\right][\mathrm{OAc}]+\mathrm{H}_{2} \mathrm{O}$ (plot a) or $\left[\mathrm{P}_{4444}\right][\mathrm{OAc}]+\mathrm{DMSO}$ (plot b) mixtures of different composition: $x_{\text {cosolvent }}=0.20$ (green, circles) or $x_{\text {cosolvent }}=0.40$ (red, squares). 
As for the case of pretreatment with pure $\left[\mathrm{P}_{44_{4}}\right][\mathrm{OAc}]$, the $D P$ of the cellulose pretreated with the mixtures of this ionic liquid with water or DMSO was also analysed. Thus, values of 228 and 226 were obtained in the case of pretreatment with the mixtures with water at $x_{\text {water }}=0.20$ and $x_{\text {water }}=0.40$, respectively; and 219 in the case of pretreatment with the mixture with DMSO at $x_{D M S O}=0.20$ (Table 1$)$. By comparing to the value of 228 for the untreated cellulose, it can be stated that the use of the $\left[\mathrm{P}_{44_{4}}\right][\mathrm{OAc}]+\mathrm{H}_{2} \mathrm{O}$ mixtures as pretreatment fluids, as in the case of pure $\left[\mathrm{P}_{44_{4}}\right][\mathrm{OAc}]$, do not cause any significant reduction of the length of the cellulose chains. Regarding the use of the $\left[\mathrm{P}_{44} 4_{4}\right][\mathrm{OAc}]+$ DMSO mixture, a little reduction in such length is observed, although the potential for utilisation of the thus pretreated cellulose in applications requiring the retention of fibrous properties is essentially preserved.

Relationship between crystallinity index and rate of hydrolysis. A relationship of the reactivity of the cellulose with its crystallinity index has been established by different authors in the literature. ${ }^{24,25}$ The results of diffractometry and hydrolysis kinetics presented herein, for the non-pretreated cellulose and for all six cellulose samples pretreated at different

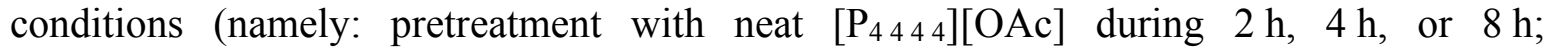
pretreatment with $\left[\mathrm{P}_{4} 4_{4}\right][\mathrm{OAc}]+\mathrm{H}_{2} \mathrm{O}$ during $2 \mathrm{~h}$ with water molar fraction of 0.20 or 0.40 ; and pretreatment with $\left[\mathrm{P}_{44} 4_{4}\right][\mathrm{OAc}]+$ DMSO during $2 \mathrm{~h}$ with DMSO molar fraction of 0.20), also suggest the existence of such a relationship. In Figure 7, the percentage of conversion of cellulose samples in the enzymatic hydrolysis reaction is plotted against the crystallinity index of those cellulose samples, for different fixed hydrolysis times. For the different reaction times analysed $(250,500$, and $1500 \mathrm{~min})$, a rough decreasing trend can be 
observed, with the degree of conversion being higher as the crystallinity of the sample is lower. Thus, from this point of view, and among all the variations investigated in the present work, the pretreatment of cellulose with the mixture of $\left[\mathrm{P}_{4444}\right][\mathrm{OAc}]+$ DMSO $\left(x_{D M S O}=\right.$ $0.20)$ would be preferred to improve its reactivity.

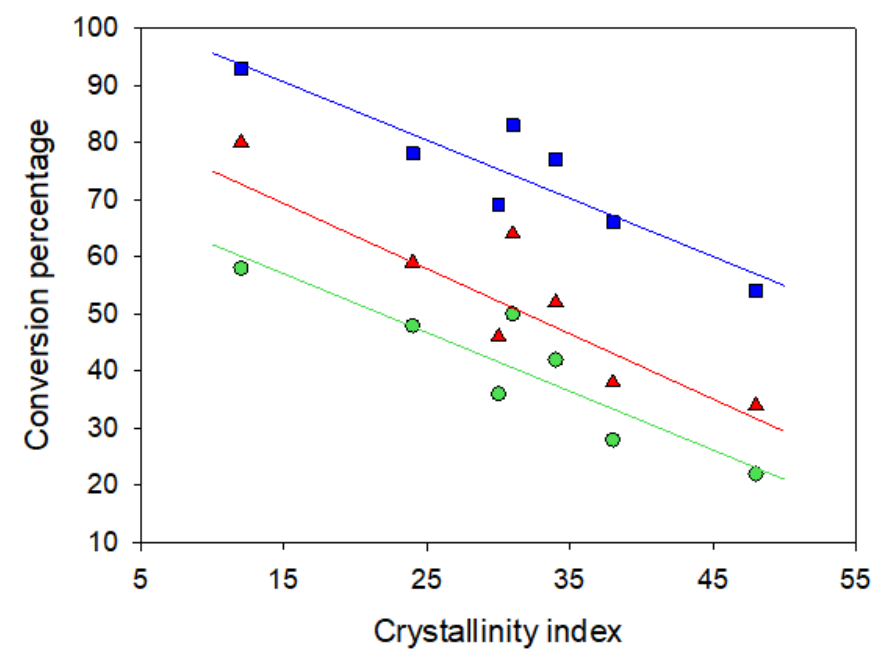

Figure 7. Conversion of the enzymatic hydrolysis of cellulose, as a function of the crystallinity index of the cellulose sample, for selected reaction times (from bottom to top): $250 \mathrm{~min}$ (green, circles), $500 \mathrm{~min}$ (red, triangles), and $1500 \mathrm{~min}$ (blue, squares). The conversion values at the specified times were approximated as linear interpolations in the respective hydrolysis time courses. Lines correspond to the best linear fit for each series, and are provided as guide to the eye.

To sum up, crystallinity reduction of cellulose has been achieved by means of a mild pretreatment, leading to improved reactivity (as illustrated by improved kinetics of enzymatic hydrolysis). Moreover, the pretreatment proposed does not negatively affect the thermal stability of the pretreated cellulose or its degree of polymerisation. All of this is combined 
with an easier recovery of the ionic liquid used as pretreatment fluid. Therefore, the work reported herein constitutes a basis of great potential for the future development of low-cost non-dissolving processes for the production of cellulose-derived chemicals and materials.

\section{ASSOCIATED CONTENT}

Supporting information. The Supporting Information is available free of charge on the ACS Publications website at DOI:

Supplementary experimental details, NMR spectra of the synthesised ionic liquid, UVvis spectrophotometric calibration line for determination of the ionic liquid in the aqueous washings, TGA and DSC thermograms of the ionic liquid, fit of the kinetics of thermal decomposition of the ionic liquid to an Arrhenius-type equation, and microscope images evidencing the non-dissolving character of the proposed pretreatment.

\section{AUTHOR INFORMATION}

\section{Corresponding Author}

*E-mail: hector.rodriguez@usc.es. Tel.:+34 881816804

\section{ORCID}

Carlos A. Pena: 0000-0002-5195-1952

Ana Soto: 0000-0001-9672-9004 
Alistair W. T. King: 0000-0003-3142-9259

Héctor Rodríguez: 0000-0002-6447-3590

\section{Notes}

The authors declare no competing financial interest.

\section{ACKNOWLEDGMENTS}

The authors are grateful to Xunta de Galicia for support through project ED431B 2017/023 and the Galician Network of Ionic Liquids (ED431D 2017/06) and the CRETUS Strategic Partnership (ED431E 2018/01), co-funded by the European Regional Development Fund. The authors would also like to thank Dr. Thelmo A. Lu-Chau for advice and discussion on experimental issues. The use of RIAIDT-USC analytical facilities is also acknowledged.

\section{REFERENCES}

(1) Klemm, D.; Philipp, B.; Heinze, T.; Heinze, U.; Wagenknecht, W. Comprehensive Cellulose Chemistry; Wiley-VCH: Weinheim, Germany, 1998.

(2) Nishiyama, Y.; Langan, P.; Chanzy, H. Crystal Structure and Hydrogen-Bonding System in Cellulose I $\beta$ from Synchrotron X-ray and Neutron Fiber Diffraction. J. Am. Chem. Soc. 2002, 124, 9074-9082, DOI 10.1021/ja0257319. 
(3) Nishiyama, Y.; Sugiyama, J.; Chanzy, H.; Langan, P. Crystal Structure and Hydrogen Bonding System in Cellulose $\mathrm{I}_{\alpha}$ from Synchrotron X-ray and Neutron Fiber Diffraction. $J$. Am. Chem. Soc. 2003, 125, 14300-14306, DOI 10.1021/ja037055w.

(4) Nagarajan, S.; Skillen, N. C.; Irvine, J. T. S.; Lawton, L. A.; Robertson, P. K. J. Cellulose II as bioethanol feedstock and its advantages over native cellulose. Renew. Sus. Energy Rev. 2017, 77, 182-192, DOI 10.1016/j.rser.2017.03.118.

(5) Langan, P.; Nishiyama, Y.; Chanzy, H. X-ray Structure of Mercerized Cellulose II at $1 \AA$ Resolution. Biomacromol. 2001, 2, 410-416, DOI 10.1021/bm005612q.

(6) Duchemin, B. J. C. Mercerisation of cellulose in aqueous $\mathrm{NaOH}$ at low concentrations. Green Chem., 2015, 17, 3941-3947, DOI 10.1039/C5GC00563A.

(7) Park, S.; Baker, J. O.; Himmel, M. E.; Parilla, P. A.; Johnson, D. K. Cellulose crystallinity index: measurement techniques and their impact on interpreting cellulase performance. Biotechnol. Biofuels 2010, 3:10, DOI 10.1186/1754-6834-3-10.

(8) Dibble, D. C.; Li, C.; Sun, L.; George, A.; Cheng, A.; Çetinkol, Ö. P.; Benke, P.; Holmes, B. M.; Singh, S.; Simmons, B. A. A facile method for the recovery of ionic liquid and lignin from biomass pretreatment. Green Chem. 2011, 13, 3255-3264, DOI 10.1039/C1GC15111H.

(9) Swatloski, R. P., Spear, S. K.; Holbrey, J. D.; Rogers, R. D. Dissolution of cellulose with ionic liquids. J. Am. Chem. Soc. 2002, 124, 4974-4975, DOI 10.1021/ja025790m.

(10) Wang, H.; Gurau, G.; Rogers, R. D. Ionic liquid processing of cellulose. Chem. Soc. Rev. 2012, 41, 1519-1537, DOI 10.1039/c2cs15311d. 
(11) Zhang, Q.; Benoit, M.; De Oliveira Vigier, K.; Barrault, J.; Jérôme, F. Green and Inexpensive Choline-Derived Solvents for Cellulose Decrystallization. Chem. Eur. J. 2012, 18, 1043-1046, DOI 10.1002/chem.201103271.

(12) Liu, Q.-P.; Hou, X.-D.; Li, N.; Zong, M.-H. Ionic liquids from renewable biomaterials: synthesis, characterization and application in the pretreatment of biomass. Green Chem. 2012, 14, 304-307, DOI 10.1039/c2gc16128a.

(13) Sun, N.; Parthasarathi, R.; Socha, A. M.; Shi, J.; Zhang, S.; Stavila, V.; Sale, K. L.; Simmons, B. A.; Singh, S. Understanding pretreatment efficacy of four cholinium and imidazolium ionic liquids by chemistry and computation. Green Chem. 2014, 16, 2546-2557, DOI 10.1039/c3gc42401d.

(14) Holding, A. J.; Heikkilä, M.; Kilpeläinen, I.; King, A. W. T. Amphiphilic and PhaseSeparable Ionic Liquids for Biomass Processing. ChemSusChem 2014, 7, 1422-1434, DOI $10.1002 /$ cssc. 201301261 .

(15) Holding, A. J.; Parviainen, A.; Kilpeläinen, I.; Soto, A.; King, A. W. T.; Rodríguez, H. Efficiency of hydrophobic phosphonium ionic liquids and DMSO as recyclable cellulose dissolution and regeneration media. $R S C A d v$. 2017, 7, 17451-17461, DOI $10.1039 / \mathrm{c} 7 \mathrm{ra} 01662 \mathrm{j}$.

(16) Mikkola, S. K.; Robciuc, A.; Lokajová, J.; Holding, A. J.; Lämmerhofer, M.; Kilpeläinen, I.; Holopainen, J. M.; King, A. W. T.; Wiedmer, S. K. Impact of Amphiphilic Biomass-Dissolving Ionic Liquids on Biological Cells and Liposomes. Environ. Sci. Technol. 2015, 49, 1870-1878, DOI 10.1021/es505725g. 
(17) Ruokonen, S.-K.; Sanwald, C.; Sundvik, M.; Polnick, S.; Vyavaharkar, K.; Duša, F.; Holding, A. J.; King, A. W. T.; Kilpeläinen, I.; Lämmerhofer, M.; Panula, P.; Wiedmer, S. K. Effect of Ionic Liquids on Zebrafish (Danio rerio) Viability, Behavior, and Histology; Correlation between Toxicity and Ionic Liquid Aggregation. Environ. Sci. Technol. 2016, 50, 7116-7125, DOI 10.1021/acs.est.5b06107.

(18) Ahvenianen, P.; Kontro, I.; Svedson, K. Comparison of simple crystallinity determination methods by $\mathrm{X}$ - ray diffraction for challenging cellulose I materials. Cellulose 2016, 23, 1073-1086, 10.1007/s10570-016-0881-6.

(19) The United States Pharmacopeia USP 41 and The National Formulary NF 36; United States Pharmacopeial Convention: Rockville, MD, USA, 2017.

(20) Smiglak, M.; Bridges, N. J.; Dilip, M.; Rogers, R. D. Direct, atom efficient, and halidefree syntheses of azolium azolate energetic ionic liquids and their eutectic mixtures, and method for determining eutectic composition. Chem. Eur. J. 2008, 14, 11314-11319, DOI 10.1002/chem.200801811.

(21) Clough, M. T.; Geyer, K.; Hunt, P. A.; Mertes, J.; Welton, T. Thermal decomposition of carboxylate ionic liquids: trends and mechanism. Phys. Chem. Chem. Phys. 2013, 15, 20480-20495, DOI 10.1039/c3cp53648c.

(22) Wu, Z.; Xu, J.; Gong, J.; Li, J.; Mo, L. Preparation, characterization and acetylation of cellulose nanocrystal allomorphs. Cellulose 2018, 25, 4905-4918, 10.1007/s10570-0181937-6. 
(23) Hirota, M.; Tamura, N.; Saito, T.; Isogai, A. Water dispersion of cellulose II nanocrystals prepared by TEMPO-mediated oxidation of mercerized cellulose at $\mathrm{pH} 4.8$. Cellulose 2010, 17, 279-288, DOI 10.1007/s10570-009-9381-2.

(24) Hall, M.; Bansal, P.; Lee, J. H.; Realff, M. J.; Bommarius, A. S. Cellulose crystallinity - a key predictor of the enzymatic hydrolysis rate. FEBS J. 2007, 277, 1571-1582, DOI 10.1111/j.1742-4658.2010.07585.x.

(25) Li, L.; Zhou, W.; Wu, H.; Yu, Y.; Liu, F.; Zhu, D. Relationship between crystallinity index and enzymatic hydrolysis performance of celluloses separated from aquatic and terrestrial plants materials. BioResources. 2014, 9, 3993-4005, DOI 10.15376/biores.9.3.3993-4005. 


\section{FOR TABLE OF CONTENTS USE ONLY}

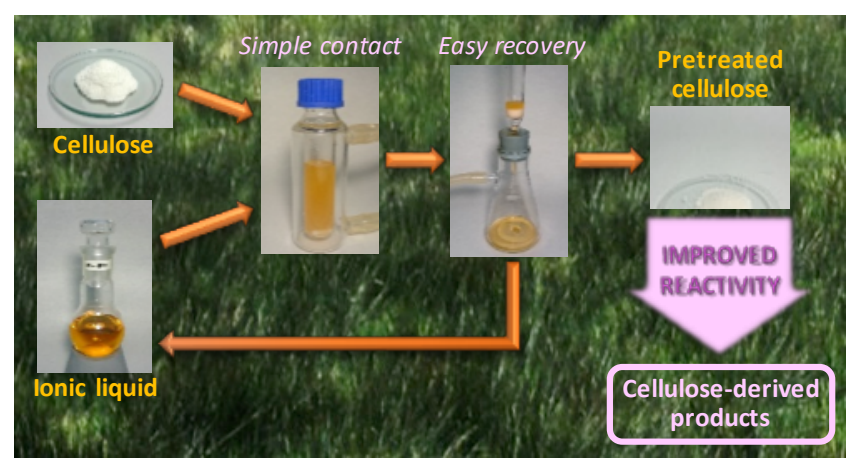

Cellulose easily recovered by filtration from a simple solid-liquid contact pretreatment with tetrabutylphosphonium acetate exhibits lower crystallinity and improved reactivity. 